\title{
Socio-economic profile of craftsmen involved in Mojari craft of Rajasthan and Jutti craft of Punjab
}

\author{
Simerjeet Kaur and Karanjeet Kaur
}

Received: 20.03.2018; Revised: 06.10.2018; Accepted: 20.10.2018

See end of the paper for authors' affiliations Simerjeet Kaur Department of Home Science, Jai Narain Vyas University, Jodhpur (Rajasthan) India
ABSTRACT : A study was conducted to know about socio-economic scale for craftsmen in involves in Mojari craft in Rajasthan and Jutti craft in Punjab state. To devise? And test a new instrument to measure socio-economic status of craftsmen in both states. By process of random sampling, a sample of 150 respondents of both states Rajasthan and Punjab were selected. Urban and Rural respondents were selected with their families. According to socio-economic scale. It was found that maximum number of the respondents $(61.33 \%)$ had monthly income between 1500-5000/-, $(28 \%)$ respondents earn $(04.00 \%)$ respondents earn $10000-15000$ and very few $(02.00 \%)$ lie in the category of monthly income above Rs.15000 and (04.67 \%) respondents not given response about their income in Rajasthan. In Punjab data reveals that some respondents $(18.67 \%$ ) had monthly income between 1500-5000/- maximum number of respondents earn (35.33\%), 10000-15000 per month and (31.33\%) had (31.33\%) monthly. Some respondents $(13.33 \%)$ had monthly income above $15000 /-$ and $(01.33 \%)$ respondents did not revered about their income. Major finding of the study in Rajasthan that craftsmen of mojari craft had very poor income level as compared to Punjab. Most of craftsmen families of Rajasthan had poor socio-economic level.

KEY WORDS: Socioe-conomic status, Scale, Income, Craftsmen

- HOW TO CITE THIS PAPER : Kaur, Simerjeet and Kaur, Karanjeet (2018). Socio-economic profile of craftsmen involved in Mojari craft of Rajasthan and Jutti craft of Punjab. Asian J. Home Sci., 13 (2) : 482486, DOI: 10.15740/HAS/AJHS/13.2/482-486. Copyright@ 2018: Hind Agri-Horticultural Society. 